[CONTRtBution FROM the Department OF Chemistry OF the University OF KANSAS.]

\title{
THE REACTIONS OF THE FORMAMIDINES. VIII. SOME THIAZOLIDONE DERIVATIVES.
}

\author{
By F. B. Dains, Roy Irvin and C. G. Harreil. \\ Received November 22, 1920.
}

In a previous paper ${ }^{1}$ some preliminary experiments showed that the complex $-\mathrm{CO}-\mathrm{CH}_{2}-\mathrm{S}$ in the 4-thiazolidones exhibited the general properties of an acid methylene grouping and combined with the formamidines yielding derivatives in which the methylene hydrogen was replaced by the aminomethylene complex, $>\mathrm{CH}_{2}+\mathrm{RN}-\mathrm{CHNHR}=$ $>\mathrm{C} . \mathrm{CHNHR}+\mathrm{RNH}_{2}$.

The experimental results which follow continue this investigation and describe the preparation of various 4-thiazolidones and show in somewhat greater detail that they are all characterized by the same reactivity of the methylene hydrogen toward benzaldehyde and the substituted formamidines.

\section{Preparation of the 4-Thiazolidones. (4-Ketotetrahydro-thiazoles). \\ 2-m-Tolylimino-3-m-tolyl-4-thiazolidone,

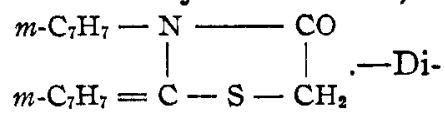

$m$-tolyl-thiourea $(75 \mathrm{~g}$.$) , chloro-acetic acid (30 \mathrm{~g}$.$) and alcohol (200 cc.)$ were boiled for several hours under a reflux condenser. Three compounds were obtained: $m$-toluidine hydrochloride, a small amount of 2-m-tolylimino-3-m-tolyl-4-thiazolidone and the diketo derivative, 3-mtolyl-thiazoledione (m. p. $90^{\circ}$ ). This, which was the main product, ${ }^{2}$ was formed by the hydrolysis in the acid solution of the 2 - $m$-tolyl-imino compound. The same type of hydrolysis occurred to a large extent in other cases where the free chloro-acetic acid was used.

Good yields of the pure thiazolidones varying from 60 to $80 \%$ were abtained, however, by the addition of enough pyridine to combine with the free acid. The general procedure was to heat the substituted thiourea in alcoholic solution for an hour with ethyl chloro-acetate and pyridine (one mol) or chloro-acetic acid and pyridine ( 2 mols). Under these conditions either none of the diketo-thiazole was obtained or the amount was very small.

2-m-Tolyl-imino-3-m-tolyl-4-thiazolidone was moderately soluble in organic solvents and crystallized from alcohol in yellow prisms, which melted at $154-5^{\circ}$.

Calc. for $\mathrm{C}_{17} \mathrm{H}_{18} \mathrm{ON}_{2} \mathrm{~S}: \mathrm{N}, 9.46$. Found: $9.20,9.54$.

2-p-Tolyl-imino-3-p-tolyl-4-thiazolidone crystallized from alcohol in

1 Dains and Stevenson, This Journal, 38, 1841 (1916).

2 Beckurts and Frerichs, Arch. Pharm., 253, 238 (1915). 
flat, pale yellow prisms, which melted at $127^{\circ} .1^{1}$ This has previously been prepared from bromo-acetic acid and the thiourea, but the melting point given was $115^{\circ}$.

Calc. for $\mathrm{C}_{17} \mathrm{H}_{18} \mathrm{ON}_{2} \mathrm{~S}: \mathrm{N}, 9.46$. Found: 9.40 .

Hydrochloride. - When the di-p-tolyl-4-thiazolidone was dissolved in benzene and dry hydrogen chloride passed into the solution, a gummy precipitate was formed, which, on standing, became crystalline. It then melted at $195-205^{\circ}$ with decomposition.

Calc. for $\mathrm{C}_{17} \mathrm{H}_{16} \mathrm{ON}_{2} \mathrm{~S}, \mathrm{HCl}: \mathrm{HCl}$, 10.97. Found: 11.45, 11.51 .

The hydrochloride was readily hydrolyzed, when heated with $N$ potassium hydroxide solution, with the formation of di-p-tolyl-urea (m. p. $\left.264^{\circ}\right)$

Calc. for $\mathrm{C}_{15} \mathrm{H}_{10} \mathrm{ON}_{2}: \mathrm{N}, 11.66$. Found: $11.70,11.80$.

3-p-Tolyl-2,4-thiazoledione, which has been prepared by other methods, ${ }^{2}$ can be readily made by hydrolyzing the di-tolyl derivative in alcoholic hydrogen chloride solution. It is also the main product isolated in the synthesis of the di-p-tolyl-thiazolidone with chloro-acetic acid without the addition of pyridine. It crystallized from hot water in fine needles which melted at $162^{\circ}$.

Calc. for $\mathrm{C}_{10} \mathrm{H}_{9} \mathrm{O}_{2} \mathrm{NS}: \mathrm{N}, 6.76$. Found: $6.68,6.90$.

2-p-Bromo-phenyl-imino-3-p-bromophenyl - 4 - thiazolidone.-Fry's method $^{3}$ gave good results in the preparation of the needed di- $p$-bromodiphenyl-thiourea, which was also obtained in a $57.5 \%$ yield on boiling the ammonium salt of $p$-bromo-phenyl-dithiocarbamate $\left(\mathrm{BrC}_{6} \mathrm{H}_{4} \mathrm{NHCSS}\right.$ $\mathrm{NH}_{4}$ ) with water. The gray powder which was deposited crystallized from alcohol in long, white needles, which melted at $188^{\circ}$. The melting point for the thiourea recorded in Richter is $180^{\circ}$.

Calc. for $\mathrm{C}_{13} \mathrm{H}_{10} \mathrm{~N}_{2} \mathrm{Br}_{2} \mathrm{~S}: \mathrm{N}, 7.26$. Found: 7.57 .

The thiazolidone which melted at $183^{\circ}$ was easily soluble in alcohol. more so in chloroform or carbon tetrachloride.

Calc. for $\mathrm{C}_{15} \mathrm{H}_{10} \mathrm{ON}_{2} \mathrm{Br}_{2} \mathrm{~S}: \mathrm{N}, 6.57$. Found: 6.20 .

2-p-Chloro-phenyl-imino-3-p-chlorophenyl-4-thiazolidone.-This was obtained in the usual manner from the thiourea. ${ }^{4}$ It crystallized from alcohol in pale yellow crystals, which melted at $165^{\circ}$.

Calc. for $\mathrm{C}_{10} \mathrm{H}_{10} \mathrm{ON}_{2} \mathrm{Cl}_{2} \mathrm{~S}: \mathrm{N}, 8.32$. Found: $8.48,8.25$.

\section{Synthesis of 4-Thiazolidones from Mixed Thioureas.}

When a thiourea of the type RNHCSNHR' is heated with chloroacetic acid, it is evident that 2 isomeric products may result.

1 Pozzi-Escot, Compt. rend., I39, 1032 (1904).

2 Ber., I3, 1579 (1880); 2 I, 976 (1888).

B Fry, This Journal, 35, 1539 (1913).

* A $50 \%$ yield of the di-p-chloro-diphenyl-thiourea was obtained by simply boiling a water solution of the ammonium-p-chlorophenyl-dithiocarbamate. 


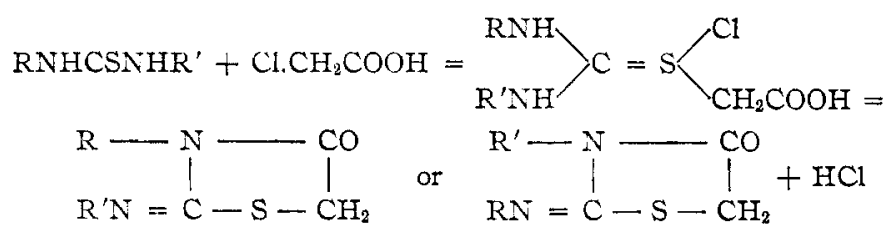

That there seems to be a selective action is shown ${ }^{1}$ by the fact that thus far only one of the possible isomers has been isolated. The conditions which control the choice are under investigation and it is hoped that enough definite experimental evidence can be obtained to throw light upon the reaction.

2-Phenylimino-3-p-bromophenyl-4-thiazolidone. - Crystallized from alcohol in thick, colorless prisms, which contained bromine and melted at $175-6^{\circ}$.

Calc. for $\mathrm{C}_{15} \mathrm{H}_{11} \mathrm{ON}_{2} \mathrm{BrS}: \mathrm{N}, 8.07$. Found: $8.02,8.28$.

3-p-Bromophenyl-2,4-thiazoledione.-When the 2-phenylimino-3-pbromophenyl-4-thiazolidone was hydrolyzed with hydrochloric acid, aniline and the diketo compound were obtained, thus proving the structure of the original compound. The white needles deposited from alcohol or hot water melted at $130^{\circ}$. The same thiazoledione together with $p$-bromo-aniline was formed by the hydrolysis of the 2-p-bromophenylimino-3-p-bromophenyl-4-thiazolidone.

Calc. for $\mathrm{C}_{8} \mathrm{H}_{6} \mathrm{O}_{2} \mathrm{NBrS}: \mathrm{N}, 5.15$. Found: 5.12 .

2-Phenylimino-3-m-bromophenyl-4-thiazolidone was readily soluble in alcohol and melted at $171^{\circ}$.

Calc. for $\mathrm{C}_{16} \mathrm{H}_{11} \mathrm{ON}_{2} \mathrm{BrS}: \mathrm{N}, 8.07$. Found: $7.83,8.08$.

2-Phenylimino-3-p-chlorophenyl-4-thiazolidone was prepared in the usual manner from the thiourea, chloro-acetic acid, pyridine and alcohol. It was necessary to heat the mixture for a number of hours to bring about the reaction. The yield of purified material was only $21 \%$. This was due partially to its further hydrolysis since there was also isolated di-pchloro-diphenylurea.

Calc.: N, 9.97. Found: 9.80 .

The thiazolidone crystallized from alcohol in which it was difficultly soluble in thick, colorless prisms, which melted at $184-5^{\circ}$.

Calc. for $\mathrm{C}_{15} \mathrm{H}_{11} \mathrm{ON}_{2} \mathrm{ClS}: \mathrm{N}, 9.26$. Found: $9.36,9.44$.

3-p-Chlorophenyl-2,4-thiazoledione.-The structure of the original thiazolidone was shown by the fact that when hydrolyzed it gave aniline and a diketo compound with the p-chlorophenyl group in the 3 position, which crystallized from alcohol in colorless needles and melted at $136-7^{\circ} .{ }^{2}$

${ }^{1}$ Dains, This Journal, 28, 1183 (1906); Dains, Roberts, Brewster, ibid., 38, 137 (1916)

"Beckurts and Frerichs, Arch. Pharm., 253, 244 (1915), obtai ned this from the 2-imino-3-chlorophenyl-4-thiazolidone and record a melti gg point of $145^{\circ}$. 
The same product was formed when the di-p-chlorophenyl-thiazolidone was hydrolyzed with alcoholic hydrochloric acid.

Calc. for $\mathrm{C}_{9} \mathrm{H}_{8} \mathrm{O}_{2} \mathrm{NClS}: \mathrm{N}, 6.21$. Found: 6.58 .

2-m-Nitrophenyl-imino-3-phenyl-4-thiazolidone.-When the mono$m$-nitro-diphenyl-thiourea ${ }^{1}$ was treated with chloro-acetic acid or ethyl chloro-acetate under various conditions, it formed a gummy non-crystalline mass, which could not be purified sufficiently for analysis. That it consisted essentially of this thiazolidone was shown by its reactions. Thus, when heated with benzaldehyde a benzal derivative was formed and it gave on hydrolysis $m$-nitro-aniline and 3-phenyl-2,4-thiazoledione which melted at $148^{\circ}$.

Calc. for $\mathrm{C}_{9} \mathrm{H}_{7} \mathrm{O}_{2} \mathrm{NS}: \mathrm{N}, 7.26$. Found: 7.21 .

It is of interest to note that in this instance the substituted phenyl group is at position 2 and not at position 3 , as in the case of the monochloro- or bromo-diphenyl-thiazolidones.

\section{5-Benzal Derivatives of the Substituted Thiazolidones.}

2- $m$-Tolylimino-3-m-tolyl - 5-benzal - 4 - thiazolidone.-It has been shown in numerous instances that the methylene group of the 4-thiazolidones condensed with aldehydes in solution in the presence of piperidine, sodium ethylate, sulfuric acid, etc. ${ }^{2}$ Experiment showed, however, that the use of a solvent or condensing agent was unnecessary. Thus, when the $m$-tolyl derivative was heated with benzaldehyde at $150^{\circ}$ for 5 hours an $83 \%$ yield of the benzal compound was obtained. It was almost insoluble in hot alcohol and was best purified by solution in hot chloroform and cautious precipitation with alcohol. The pale yellow microscopic needles melted at $175-7^{\circ}$.

Calc. for $\mathrm{C}_{24} \mathrm{H}_{20} \mathrm{ON}_{2} \mathrm{~S}: \mathrm{N}, 7.29$. Found: 7.11, 7.16.

The following compounds were prepared in order to further characterize the new thiazolidones and to show the applicability of this method of synthesis.

2-p-Tolylimino-3-p-tolyl-5-benzal-4-thiazolidone formed yellow needles from alcohol which melted at $197^{\circ}$ and which were readily soluble in carbon tetrachloride, chloroform and glacial acetic acid.

Calc. for $\mathrm{C}_{24} \mathrm{H}_{20} \mathrm{ON}_{2} \mathrm{~S}: \mathrm{N}, 7.29$. Found: 7.50, 7.61.

When the benzal derivative was boiled in alcoholic potassium hydroxide solution it gave di-p-tolyl urea and a small amount of a compound which melted at $208^{\circ}$ and proved to be the 3-p-tolyl-5-benzal-2-4-thiazoledione. This was difficultly soluble in alcohol, from which it crystallized in short white needles, which melted at $210^{\circ}$.

Calc. for $\mathrm{C}_{17} \mathrm{H}_{13} \mathrm{O}_{2} \mathrm{NS}: \mathrm{N}, 4.75$. Found: $4.60,4.54$.

1 This melted at $160^{\circ}$. Richter gives $155^{\circ}$.

${ }^{2}$ Andreasch, Monatsh., 24, 516 (1903); 38, 121 (1917); Kucera, ibid., 35, 144 (1914); Wheeler and Jamieson, Thrs Journal, 25, 367 (1903). 
The corresponding derivative, 3-p-tolyl-5-m-nitro-benzal-2-4-thiazolidone was almost insoluble in alcohol; the brownish-yellow crystals from chloroform melted at $230^{\circ}$.

Calc. for $\mathrm{C}_{17} \mathrm{H}_{12} \mathrm{O}_{4} \mathrm{~N}_{2} \mathrm{~S}: \mathrm{N}, 8.24$. Found: $8.45,8.50$.

2-p-Bromophenyl-imino-3- $p$-bromophenyl - 5 - benzal - 4 - thiazolidone formed light yellow crystals, which melted at $220^{\circ}$. It was very difficultly soluble in alcohol, but readily so in chloroform and glacial acetic acid.

Calc. for $\mathrm{C}_{22} \mathrm{H}_{34} \mathrm{ON}_{2} \mathrm{Br}_{2} \mathrm{~S}: \mathrm{N}, 5.45$. Found: $5.50,5.57$.

2-p-Chlorophenyl-imino-3-chlorophenyl-5-benzal-4-thiazolidone crystallized from alcohol in greenish-yellow needles which melted at $213^{\circ}$.

Calc. for $\mathrm{C}_{22} \mathrm{H}_{14} \mathrm{ON}_{2} \mathrm{Cl}_{2} \mathrm{~S}: \mathrm{N}, 6.59$. Found: $6.49,6.60$.

2-Phenylimino-3-p-bromophenyl-5-benzal-4-thiazolidone formed light yellow plates with a melting point of $197-9^{\circ}$.

Calc. for $\mathrm{C}_{22} \mathrm{H}_{12} \mathrm{ON}_{2} \mathrm{BrS}: \mathrm{N}, 6.44$. Found: $6.43,6.14$.

2-Phenylimino-3-m-bromophenyl-5-benzal-4-thiazolidone was almost insoluble in alcohol and sparingly so in glacial acetic acid. The pale yellow needles melted at $200-1^{\circ}$.

Calc. for $\mathrm{C}_{22} \mathrm{H}_{15} \mathrm{ON}_{2} \mathrm{ClS}: \mathrm{N}, 7.16$. Found: 7.30 .

2-m-Nitrophenyl-imino-3-phenyl-5-benzal-4-thiazolidone was a yellow crystalline compound which melted at $193^{\circ}$.

Calc. for $\mathrm{C}_{22} \mathrm{H}_{15} \mathrm{O}_{3} \mathrm{~N}_{3} \mathrm{~S}: \mathrm{N}, 10.48$. Found: 10.69

II. Condensation Reactions with the Substituted Formamidines; Synthesis of Derivatives of the General Type,

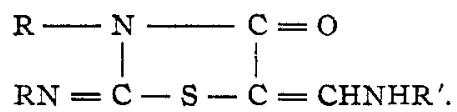

These compounds were formed by simply heating the components in an oil-bath. In general the yields were from $50-60 \%$; too prolonged heating gave rise to tarry decomposition products which lowered the yield and rendered more difficult the purification of the products.

2-p-Tolylimino - 3-p-tolyl- 5 - anilino - methylene - 4 - thiazolidone. A molar mixture of the thiazolidone and diphenyl formamidine was heated for 3 hours hetween $140^{\circ}$ and $160^{\circ}$. From this melt were separated aniline and the new compound which crystallized from alcohol in bright yellow needles which melted at $168^{\circ}$. It was fairly soluble in alcohol and readily so in chloroform, carbon tetrachloride and in acetic acid. When boiled with alcoholic potassium hydroxide it gave di-ptolylurea.

Calc. for $\mathrm{C}_{24} \mathrm{H}_{21} \mathrm{ON}_{3} \mathrm{~S}: \mathrm{N}, 10.53$. Found: $10.74,10.90$.

2- $p$-Tolylimino-3- $p$-tolyl-5- $\beta$-naphthyl-aminomethylene-4-thiazolidone and $\beta$-naphthylamine are the resulting products when di- $\beta$-naphthyl- 
formamidine and the thiazole were heated for one hour between $200^{\circ}$ and $230^{\circ}$. The new thiazolidone formed yellow crystals which melted at $215^{\circ}$. Calc. for $\mathrm{C}_{28} \mathrm{H}_{23} \mathrm{ON}_{3} \mathrm{~S}: \mathrm{N} .9 .36$. Found: 9.45, 9.52.

3-m-Tolyl-5-anilino-methylene-2,4-thiazolidone. - When dipheny 1 formamidine and the di-m-tolyl-thiazolidone were heated under various conditions a yellow product melting between $130^{\circ}$ and $165^{\circ}$ was obtained, but not in sufficient purity for analysis. When this was boiled with an alcoholic solution of potassium hydroxide, $m$-toluidine and the diketo compound were obtained. This formed colorless needles from alcohol and melted at $211^{\circ}$.

Calc. for $\mathrm{C}_{17} \mathrm{H}_{13} \mathrm{O}_{2} \mathrm{~N}_{2} \mathrm{~S}: \mathrm{N}, 9.04$. Found: $9.28,8.88$.

That the substitution of halogen in the phenyl groups does not effect the ease of condensation with the formamidines is shown by the following instances.

2-p-Bromophenyl-imino-3-p-bromophenyl-5- $\beta$-naphthylamino-methylene-4-thiazolidone.--This crystallized from a mixture of alcohol and chloroform in fine yellow needles which melted at $190^{\circ}$.

Calc. for $\mathrm{C}_{26} \mathrm{H}_{17} \mathrm{ON}_{3} \mathrm{Br}_{2} \mathrm{~S}: \mathrm{N}, 7.26$. Found: 7.35, 7.40.

2-p-Chlorophenyl-imino-3-p-chlorophenyl-5- $\beta$-naphthylamino-methylene-4-thiazolidone.-This formed greenish-yellow crystals from alcohol which melted at $204^{\circ}$. It was readily soluble in chloroform, carbon tetrachloride and in glacial acetic acid.

Calc. for $\mathrm{C}_{26} \mathrm{H}_{17} \mathrm{ON}_{3} \mathrm{Cl}_{2} \mathrm{~S}: \mathrm{N}, 8.58$. Found: $8.50,8.70$.

2-Phenylimino-3-p-chlorophenyl-5-anilino-methylene - 4 - thiazolidone is easily soluble in alcohol, from which it crystallized in yellow needles, with a melting point of $180^{\circ}$.

Calc. for $\mathrm{C}_{22} \mathrm{H}_{18} \mathrm{ON} 4 \mathrm{Cl}: \mathrm{N}, 10.36$. Found: 10.64 .

\section{Summary.}

A number of new disubstituted 4-thiazolidones and their benzal derivatives have been prepared, containing either the same or different groups at Positions 2 and 3.

The methylene group in these 4 -thiazolidones has been found to react with the substituted formamidines giving derivatives of the type

LATRENCE, RANSAS.

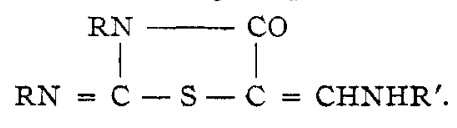

